\title{
KRONIK
}

\section{Kadınların Sürdürülebilir Gelişme için Örgütlenme Deneyimlerinden ve Toplumsal Cinsiyet Analizinden Íklim Değişikliğini Anlamak}

Arş. Gör. Ezgi Kovancı, Ankara Üniversitesi, Sosyal Bilimler Enstitüsü, Kent ve Çevre Bilimleri Anabilim Dalı Doktora Öğrencisi

İklim değişikliği, dünyayı etkileyen ve kökü toplumsal eşitsizliklere dayanan karmaşı toplumsal bir sorundur. İklim değişikliğinin etkileriyle başa çıkmak ve etkilerini hafifletmek açısından cinsiyet önemli bir faktör olarak kendini göstermektedir. Kadınlar erkeklere oranla iklim değişikliğinin etkilerine karşı daha savunmasız olmalarına karşın, iklim değişikliğini azaltma ve iklim değişikliğine uyum konusunda önemli bilgi ve beceriye sahiptirler.

Bu yazıda Irene Dankelman tarafindan yazılan ve 2002 yılında "Gender and Development" Dergisi'nde yayımlanan "Climate Change: Learning from Gender Analysis and Women's Experiences of Organising for Sustainable Development" isimli makale üzerinden iklim değişikliği ve kadınların örgütlenme deneyimleri birlikteliğinde çevre politikasına ve uygulamalarına ilişkin değerlendirmelerde bulunulacaktır.

Öncelikle, iklim değişikliğinin önemli sayılabilecek siyasi ve sosyoekonomik yönleri olduğu savunulmaktadır. Aynı zamanda, küreselleşmenin getirdiği sorunların başında gelen refah ve güç dağılımının eşit olmaması dışında; küreselleşmeyle birlikte bozulan çevre ile cinsiyet arasında negatif bir

1 Irene Dankelman (2002), "Climate Change: Learning from Gender Analysis and Women's Experiences of Organising for Sustainable Development”, Gender \& Development, 10 (2): 21-29. 
ilişkinin var olduğu gözler önüne serilmektedir. Çalışmada, cinsiyet ve iklim değişikliği arasındaki fiili bağlantılar vurgulanmakta ve kadın katılımının sürdürülebilir kalkınma konularında ne denli önem arz ettiğinin altı çizilmektedir. İklim konusunda kadınların duyarlı girişimlerinin toplumsal cinsiyet ve iklim bağlamında önemli başarılı sonuçlar elde edeceği de savunulmaktadır.

İklim değişikliği uzak gelecekte gerçekleşecek bir olay değil, şu anda gerçekleşmekte olan bir olgudur. 1988 yılında Birleşmiş Milletler (BM) tarafından iklim değişikliği hakkında veri toplamak ve bilgi geliştirmek için kurulan "Hükümetlerarası İklim Değişikliği Paneli (IPCC)"nin, 2001 y1lında sunduğu 3. Değerlendirme Raporu'nda küresel isınmanın bir gerçeklik olduğu ve son 50 yılda gözlemlenen 1sınmanın büyük ölçüde insan etkinliklerine bağlı olarak geliştiği ortaya koyulmuştur.

\section{Íklim Değişikliğinin İnsani Boyutları}

Uluslararası iklim değişikliği paneline göre; yerel ve küresel iklim sistemlerindeki değişikliklere bakıldığında, büyük ölçüde insan müdahalesi kaynaklı olduğu görülmektedir (akt. Dankelman, 2002: 21). İnsan faaliyetlerinden kaynaklanan sera gazı emisyonlarının atmosferi değiştirmedeki payı da bunda önemli bir etkiye sahiptir. Karbondioksit ve metan gibi yüksek orandaki sera gazları yeryüzünün 1sınmasına neden olmaktadır ve bu gazlardan karbondioksit emisyonlarının \%75'i fosil yakıtların yakılması, geri kalan kısmı ise yanlış arazi kullanımı ve ormansızlaşmadan kaynaklanmaktadır. Metan emisyonlarındaki yarıdan fazla artışta ise insan faaliyetlerinin neden olduğu fosil yakıt kullanımı, büyükbaş hayvancılık, pirinç tarımı ve arazi doldurma etkilidir. $\mathrm{Bu}$ durum iklim değişikliğinden kimin sorumlu olduğu, iklim değişikliğinin farklı nüfuslarda, farklı çevre ve sektörlerde ne tür farklı olumsuz etkiler meydana getirdiği gibi soruları da gündeme getirmektedir. Şimdiye kadar bu sorulara verilen yanıtlar iklim değişikliğinin politik karaktere sahip ve gelişen bir sorun olduğunu kanıtlamaktadır.

Soruna tarihsel açıdan bakıldığında, sanayileşmiş ülkeler, hızlı sanayileşmeleri yüzünden sera gazlarının \%80'inin yayılmasına neden olmuşlardır. Sanayileşmiş ülkelerdeki toplumsal ve ekonomik gelişmeler, iklim değişikliğinin özellikle gelişmekte olan ülkeler üzerindeki olumsuz etkilerinde büyük pay sahibidirler. Şöyle ki, günümüzde atmosfer tarafından emilen söz konusu sera gazlarının büyük çoğunluğu, sanayileşmiş ülkeler tarafından tüketilmektedir. İklim Adaleti Ağı, bu ülkeler arasında sayılabilecek olan Kanada, Japonya, Amerika Birleşik Devletleri ve Avusturalya'nın BM tarafindan gerçekleştirilen iklim değişikliği müzakerelerinin ilerlemesini engellediğini ileri sürmektedir (akt. Dankelman, 2002: 22). 


\section{İklim Değişikliğinin Olumsuz Etkilerinden En Çok Kim Etkileniyor?}

İklim değişikliğinin ortaya çıkmasında fazla payları bulunmasa da iklim değişikliğinin olumsuz sonuçlarından ve ortaya çıkan felaketlerden en çok gelişmekte olan ülkeler etkilenmiştir. 1998 yılında Çin'de ve Hindistan'da karların erimesi sonucu 5.550 kişi hayatını kaybetmiş̧ir. Filipinler, Bangladeş, Karayipler ve Orta Amerika'daki tayfunlar, firtına ve kasırgalar 15.800 kişinin ölümüne neden olmuştur. 1999 'da Venezuela'da 50 bin kişi şiddetli yağışlar ve çamur seli yüzünden ölmüştür. 2000 y1lında Mozambik'te meydana gelen bir felaket; yağmur, sel ve kasırga sonucunda 800 bin kişi hasar görmesine, 700 kişinin ölümüne ve 250 bin kişinin evsiz kalmasına yol açmıştır. Bunun yanı sıra, sıtmadan ve tropik hastalıklardan hastalananların sayısında artış meydana gelmiş ve gıda üretimi olumsuz etkilenmiştir. İşin toplumsal boyutuna bakılacak olursa karşımıza çıkan tablo, bu olumsuzluklardan en çok etkilenen gelişmekte olan ülkelerdeki düşük gelirli grubun, güvenebilecekleri sigortalarının ya da belli tasarruflarının bulunmamasıdır. Sonuç olarak, ölümler, hastalıklar, yaralanmalar ve evsiz kalma gibi dramatik sayılabilecek sorunların yanı sıra bu kişiler başka ülkelere ya da bölgelere göç etmek durumunda kalmışlardır. İklim Adaleti Ağı, doğal ve çevresel felaketler nedeniyle bulundukları yerlerden ayrılmak zorunda kalan göçmenler olarak adlandırılan bu grubun yani "çevre mültecileri"nin hala BM tarafindan tanınmadığının altını çizmektedir (akt. Dankelman, 2002: 22).

\section{İnsani Güvenlik İçin Öngörülen Sonuçlar}

IPCC İkinci Çalışma Grubu Raporu, son bölgesel iklim değişikliklerinin özellikle de sıcaklık artışlarının, birçok fiziksel ve biyolojik sistemi etkilediği sonucuna varmıştır (akt. Dankelman, 2002: 22). Bazı bölgelerde taşkınların olma sıklığı artarken, çölleşme oranı da yükselmiştir. Geçim ve insan güvenliği üzerinde birtakım olumsuz etkiler ortaya çıkmaktadır:

- Pek çok tropikal ve sub-tropikal bölgelerde potansiyel mahsul veriminde genel bir azalma görülebilmektedir. Bu durum gıda güvenliği açısından; gıda kullanılabilirliği, gıdaya erişilebilirlik, gıda kullanımı ve gıda sistemlerinin sürdürülebilirliği gibi konularda önemli riskler oluşturmaktadır.

- Su kıtlığı çeken bölgelerde özellikle de sub-tropikal bölgelerde suya erişim daha da güç hale gelmektedir. 
- Sıtma gibi bulaşıcı hastalıklara ve kolera gibi su kaynaklı hastalıklara maruz kalanların sayısında artışlar yaşanmakta ve ölümler meydana gelmektedir.

- Artan yoğun yağışlar ve deniz seviyesindeki yükselme sonucunda birçok yerleşim yerindeki milyonlarca insan daha fazla sel riski altında kalmaktadır.

İklimin bulaşıcı hastalıklar ile salgınları arttırdığı ve bunların şiddetini etkilediği gerçekliği diğer çalışmalarda da ele alınmıştır. Dünya Sağlık Örgütü (WHO) Genel Direktörü Dr. Margaret Chan'in konuşmacı olarak katıldığı bir panelde, Sub-Saharan Afrika en etkili sivrisinek türlerine ve sitmanın en şiddetli şekline ev sahipliği yapmakta olduğunu vurgulamıştır (WHO, 2007). Yükselen sıcaklıklarla birlikte sıtma parazitinin yaşam döngüsü hızlanmakta ve bu durum özellikle fakir milyonlarca insanı etkilemektedir (UN-Womenwatch, 2016).

IPCC, kaynakları çok az olan ülkelerin iklim değişikliğinin olumsuz etkilerine karşı en hassas ve bu etkilere uyum sağlamak için de en az kapasiteye sahip olan ülkeler oldukları sonucuna varmıştır. İnsan topluluklarının ve doğal sistemlerin iklim değişikliğinin negatif etkilerine olan hassasiyeti, bölgeler ve nüfuslar arasında önemli ölçüde farklılık göstermektedir. Küçük adalar ve alçak kıyı alanlarının yaşayanları, deniz seviyesindeki yükselme ve kasırgalar nedeniyle ciddi toplumsal ve ekonomik risk altındadır. Bu durum da bizi iklim değişikliğine neden olanlarla, iklim değişikliğinin olumsuz sonuçlarından etkilenenler arasında eşitsizlik olduğu sonucuna götürmektedir. İklim değişikliğinin olumsuz etkileri gelişmekte olan ülkelerde ve bu ülkelerdeki yoksul insanlar üzerinde orantısız bir dağılım göstermektedir. Özellikle sağlıkta ortaya çıkan eşitsizlikler; temiz suya, gıdaya ve diğer kaynaklara erişimde git gide artacak şekilde adaletsiz bir seyir izlemektedir. İklim Adaleti Ağının belirttiği gibi; "İklim değişikliğinin çevresel adalet yönü kesinlikle yoktur". Burada Dankelman'ın neyi savunduğunu anlamak açısından iklim değişikliğinin önemli bir çevre sorunu olduğuna değinmek ve sosyal adaletsizlikle olan ilişkisini yakından kavramak gerekmektedir.

\section{Fiziksel Çevre ve Cinsiyet Analizi}

İklim değişikliği sorununun asıl sorumlusu olan gelişmiş ülkelerle, sorunun olumsuz etkilerinden en çok etkilenen gelişmekte olan ülkeler arasında dengesiz bir dağılım göstermesinin yanı sıra kadınlar ve çocuklar ile erkekler arasında da farklılıklar göstermektedir. İklimde meydana gelen değişiklikler kadınların ve erkeklerin yaşamlarını mevcut toplumsal cinsiyet dinamikleri ve eşitsizlikler nedeniyle farklı şekillerde etkilemektedir. Dankelman makalesinde iklim değişikliğinin cinsiyet boyutunun olup olmadığını tartışmakta ve iklim 
değişikliğinin toplumsal cinsiyet boyutlarını belirlemek için çevre ve cinsiyet arasındaki ilişkiyi doğru anlamak gerektiğini ve ilgili çalışmaları dikkate almanın yararlı olacağını savunmaktadır.

1980'lerin ortalarından bu yana yapılan çalışmalar doğrultusunda, çevrede meydana gelen olumsuzluklardan etkilenme açısından cinsiyet boyutu ön plana çıkmaktadır. Örneğin, kırsal alanlarda yaşayan kadınlar, çevreleriyle doğrudan etkileşim içinde oldukları için çevresel bozulmalardan orantısız şekilde daha fazla etkilenmektedirler. Yeni Delhi'de bulunan "Bilim ve Çevre Merkezi”, 1985 yılında yayınlanan Hindistan Devleti'nin Çevre Raporu'nda "Muhtemelen, çevresel yıkımlardan yoksul köy kadınlarından daha çok etkilenen başka bir grup yoktur" diye bir saptamada bulunmuştur.

Yoksulluk ve çevresel tahribatın etkisiyle ekolojik koşulların kötüye gitmesi hiç şüphesiz ki kırsal alanlarda yaşayan kadınları olumsuz etkilemektedir. "Örnek Olay" olarak çalışılmış pek çok yayın da bunu doğrular niteliktedir. Şöyle ki, toprak, su, enerji ve biyolojik çeşitliliğin kullanımı ve yönetimi kırsal alanlarda daha çok kadınların elinde olduğu için bu kaynakların bozulması da doğrudan kadınları etkilemektedir. Dankelman makalesinde Vandana Shiva'nın çalışmalarına atıfla, kadınların "toplayıcı" ve geleneksel sürdürülebilir gıda temini faktörü olmasının yanı sıra çevreyi koruma eylemlerinde de önemli rol oynadıklarını 18. yy'da Amrita Devi öncülüğünde Hindistan Rajasthan'da hayatta kalmak için bir çevre mücadelesi verdiklerini örnekleyerek vurgulamaktadır. Kadınların çevreyi koruma uğruna verdikleri mücadelelerden bir diğeri olan Coca-Cola karşıtı hareket de Dankelman'ın örneğini destekler niteliktedir. Kerala'nın küçük bir köyündeki kadınlar CocaCola karşıtı bir hareket düzenlemişler ve fabrikayı kapattırmayı başarmışlardır. Fabrika kendi faaliyeti için yerel halkın suyunu kullanmanın yanı sıra, kullanmadığ 1 suları da kirletmekteydi. Şirket atık maddeleri çevreye boşaltmakta ve bu atıkların da yağmur sularıyla birlikte pirinç tarlalarına, kanallara ve kıyılara karışmasıyla insan sağlığını tehdit eden durumlar ortaya çıkmaktadır.. Sularının kirlenmesi sonucunda temiz su kaynaklarına ulaşabilmek için kadınlar kilometrelerce yol gitmek durumunda kalıyorlardı. Fabrikanın suyu bol bir bölgede su kıtlığı yaratması karşısında kadınların bir oturma eylemi gerçekleştirmesi hem ulusal ve küresel düzeyde ses getirmiş hem de fabrikanın kapatılmasıyla başarılı şekilde sonuçlanmıştır (Shiva, 2010: 232).

\section{Íklim Değişikliği Cinsiyet Açısından Nötr mü?}

Çevre koşullarında meydana gelen değişimlerden belki de en önemlisi olan iklim değişikliği, insanlık açısından önemli bir tehdit oluşturmaktadır. Ancak cinsiyet açısından olaya bakılırsa, cinsiyet yalnızca kadınların ve 
erkeklerin çevresel değişikliklerle başa çıkma yeteneğini belirlememekte aynı zamanda altta yatan yapısal eşitsizliklerin kadınlar üzerinde orantısız bir etkiye sahip olduğu anlamına gelmektedir (UNEP, 2016a). İklim değişikliği çoğu kez teknik çözümler gerektiren bir problem olarak tanımlanmakla birlikte, cinsiyet açısından da nötr olduğu yani hem kadını hem de erkeği aynı yollarla etkilediği tartışılıyor olsa da kadınların afetleri azaltma ve önlemede, aynı zamanda iklim değişikliğinin etkilerini hafifletmede, erkeklere göre ne denli farklı roller üstlendikleri vurgulanmıştır (akt. Dankelman, 2002: 24).

Dankelman değişen cinsiyet rollerinin ve ilişkilerin iklim değişikliği tarafından çeşitli derecelerde etkilediğini beş başlık altında listelemiş̧tir.

\section{Cinsiyete Özgü Kaynak Kullanım Şekilleri Çevreye Zarar Verebilmektedir:}

Güneydeki pek çok hanede, kadınlar enerjiyi yöneten kişiler olmasına karşın genellikle enerji programlarını ve politikalarını etkileyen ve çevreye zarar veren kararlar egemen olan erkekler tarafindan alınmaktadır. Bunun yanı sıra, Kuzey ve Güney'deki petrol sektörü gibi ön plana çıkan güç odakları da fon sağlayan kuruluşların büyük çoğunluğu gibi erkek egemendir.

\section{2. İklim Değişikliğinin Toplumsal Cinsiyete İlişkin Etkileri:}

Kadınların erkeklere oranla çevreyle daha sıkı bağlantı içinde olmaları onları daha tecrübeli kılmaktadır ancak Dankelmann bu tecrübelerine rağmen "kadınlar erkeklere göre iklim değişikliğinin etkilerine karşı hassastırlar" fikrini ileri sürmektedir. Bunu destekleyen bir diğer bilgi UNEP (United Nations Environment Programme)' in “Toplumsal Cinsiyet ve Çevre Raporu”nda şu şekilde ifade edilmiştir; "Tehlikeli kimyasallar ve atık, insan sağlığını cinsiyete bakmaksızın olumsuz etkilemektedir". Ancak, toplumsal cinsiyet rolleri kadınların ve erkeklerin bu kimyasallara maruz kalma oranlarını belirlemektedir. Sanayi sektöründe çalışan erkekler evin dışında tehlikeli kimyasallara maruz kalmalarından dolayı hastalıklara yakalanmak açısından yüksek risk taşımaktadırlar. Ancak kadınlar hem ev dışında hem ev içinde söz konusu kimyasallara ve onların olumsuz etkilerine maruz kalabilmektedirler. Fizyolojik farklılıklar kadınların maruz kaldığı durumlar, onları bazı kanser türlerine yakalanma olasılıklarında daha riskli durumda olmalarına neden olmaktadır. Bunun yanı sira gelecek nesillerde de kalıcı hasarlara yol açabilecek aktarımların olabilmesi söz konusudur (UNEP, 2016b). 


\section{Azaltım ve Uyum Çabalarında Toplumsal Cinsiyet Rolleri:}

Afetlerle ilgili yapılan çeşitli çalışmalar, afet zararlarının azaltılması, uyumun gerçekleştirilebilmesi ve çevre yönetiminin yapılması açısından cinsiyetin önemli bir faktör olduğunu ortaya çıkarmaktadır. Dankelman (2002: 25), kadınların afetlerle başa çıkmak açısından erkeklere göre başarılı olduğunu savunmaktadır. Çünkü kadınların alanları tanıma açısından yerel bilgilerinin daha geniş olması, çevre yönetimi uygulamalarının daha başarılı olmasını sağlamaktadır. Kadınların, iklim değişikliğinin olumsuz etkilerine karşı savunmasız olmalarına karşın iklim değişikliğine hem uyum hem de iklim değişikliğinin etkilerini azaltma bakımından etkili aktörler oldukları açıktır. Çünkü kadınlar, değişen çevre koşullarına karşı geçim stratejileri geliştirmek konusunda oldukça iyi konumlanmışlardır. Ancak kadınların bu katkısı çoğu zaman fark edilmemektedir. Ne yazık ki, kadınlar pek çok alanda su ve toprak kullanımı konusunda sorumluluk üstlenmelerine rağmen bu kaynakların nasıl kullanılması gerektiği konusunda söz hakkına da sahip değillerdir.

\section{4. İklim Değişikliği Konusunda Toplumsal Cinsiyet Açısından Karar Verme Rolleri:}

Dankelman'ın çalışmasında daha önce de belirttiği gibi kadınlar enerji sektöründe ve enerji politikalarında üretici olarak sınırl bir rol oynamaktadırlar. İklim değişikliği müzakerelerinin neredeyse hiçbirisine kadınlar dahil edilmemiş ve toplumsal cinsiyet bakış açısına gerektiği kadar önem verilmemiştir. Marakeş’te 2001 yılında gerçekleşen İklim Değişikliği Çerçeve Sözleşmesi'ne taraf ülkeler 7. Taraflar Konferansı sırasında Samoa temsilcilerinden, kadınların müzakerelere daha eşit katılımının sağlanması için bir çağrı gelmiştir. Gelişmekte olan ülkelerde kadınların genellikle enerjinin ana kullanıcıları olduğu düşünülürse kadınların ve kadın kuruluşlarının katılımının önemi yadsınamaz bir gerçektir. Dünya nüfusunun yarısından fazlasının kadın olmasına karşın kadınlar yerel, ulusal ve küresel düzeylerde politika geliştirme, karar verme alanlarında ayrı tutulmakta ve yetersiz temsil edilmektedirler. Çevreci kadın bakanların yüzdesinde artış olmasına rağmen, İklim Değişikliği Çerçeve Sözleşmesi'ne taraf ülkeler 6. Toplantısında, heyetin yalnızca $1 / 5$ 'i kadındır. Bu yetersiz temsil, çevresel konularda politika geliştirme ve karar alma süreçlerine de yansımaktadır (UN, 2015: 5). Mevcut katılım eksikliği özellikle kırsal alanlardaki kadınların büyük ölçüde göz ardı edilmelerine neden olmakta, kadınları karar alma süreçlerinde seslerini duyurmalarından mahrum birakmaktadır. 


\section{Kapasite Geliştirme}

Dankelman kapasite geliştirmenin önemli bir odak olduğunu vurgularken, hala eğitime, öğretime ve teknolojiye erişim konusunda cinsiyet açısından eşitsizlikler olduğunun altını çizmektedir. Söz konusu eşitsizlikler giderilmeden iklim değişikliğini azaltmak açısından cinsiyete duyarlı kapasitelerin de geliştirilmesinin mümkün olamayacağı sonucuna varmaktadır. Teknolojik açıdan kapasite geliştirmenin önemli olması, su, tarım ve insan yerleşimleri gibi konularda dayanıklılığı artırması ve adaptasyon sağlaması açısından fazlasıyla önemlidir. Bunun yanı sıra iklim değişikliğiyle alakalı teknolojik gelişmelerde kadınlara özel öncelikler tanınması elzemdir. Kadınların ihtiyaçları ve toplumsal cinsiyet rolleri göz önünde bulundurularak; onların yerel bilgi, uzmanlık ve uygulamalarından yararlanılarak iklim değişikliğiyle mücadele için yararlı teknolojilerin geliştirilmesi gerekmektedir (Lambrao ve Pianna 2006: 15).

\section{Kadınların Sürdürülebilir Kalkınma İçin Örgütlenmesi}

İklim değişikliğinin toplumsal cinsiyet boyutundan bahsedilirken kadınların sadece mağdur olduklarını söylemek doğru olmaz. Çünkü birçok çalışma, kadınların çevre sorunları ve sürdürülebilir kalkınma etrafında organize olma konusunda önemli roller üstlendiklerini göstermektedir. Örneğin, 1991 yılında, 83 ülkeden 1.500 kadın Miami'de ilk olarak "Sağlıklı Yeryüzü için Dünya Kadınlar Kongresi"nde toplanmıştır. Kongrede, dünyanın her bölgesinden seçilen kadınlar, beş kadın yargıcın oluşturduğu mahkeme huzurunda ekolojik ve ekonomik yıkıma karşı olan savaşlarını çarpıcı şekilde sunmuşlardır. Bu kanıt ve deneyimlerle, kongre katılımcıları "Kadın Eylem Gündemi 21"i (WAA21) geliştirmişlerdir. Sağlıklı bir gezegen için öneriler ve eylemler içeren eylem gündemi, bir sonraki yüzyılda yerel, ulusal ve uluslararası karar vermede toplumsal cinsiyet boyutunu da içeren bir plan oluşturmak için tasarlanmıştır. Özellikle kadınların BM Çevre ve Kalkınma Konferansı (UNCED)'nın hazırlık aşamalarında aktif ve eşit katılımını teşvik etmek amaç edinilmiştir. Nitekim 1992 yılında Rio de Janeiro'da düzenlenen Konferansın hazırlık sürecinde kadınlar kendilerini daha önce benzeri olmayan bir şekilde organize etmeyi başarmışlardır.

WAA21, Konferans sürecinde cinsiyet için duyarlı ve etkili bir belge olduğunu kanıtlamış, dünya çapındaki kadın grupları için ortak bir odak noktası ve ilham kaynağı olmuştur. Gücünü, Konferans ile bağlantılı, kadınların deneyimleri, görüşleri ve vizyonlarını yansıtan bir süreç olmasından almaktadır. Ayrıca belgenin geniş kapsamı ve farklı tematik alanlardaki analizi geniş 
kullanımını ve uygulanabilmesini de etkin kılmaktadır. Belgenin zayıflığı ise sadece 1.500 kadının örnek alınarak görüşme yapılmasında yatmaktadır. Aynı zamanda dünya çapında gerçekleşen bir istişare süreci de bulunmamaktadır. Bunun sonucu olarak yerel gruplar ve bölgesel ağlar bu belge üzerinde güçlü bir sahiplik duygusundan yoksun bulunmaktadırlar. Sonuç olarak belge gelecek uygulamalar açısından bir takip planı niteliği taşımasa da önemli bir lobi belgesi olma özelliğini taşımaktadır.

Konferans'ın ayrıca "Women's Tent" ve "Planeta Famea" bünyesinde gerçekleştirdiği, pek çok kadın örgütünün toplanıp deneyimlerini paylaştıkları ve çevre-kalkınma konularında görüşlerini sundukları çalışmaları da olmuştur. As1l amaç, kadın gruplarına WAA21'de sunulan temalar üzerine STK Forumu'nda yapılan günlük toplantılara ev sahipliği yapmak adına fiziksel mekân sunmaktı. Bu proje, pek çok kadın katılımcının sürdürülebilir kalkınmaya yönelik taahhüdüne görünürlük kazandırmak açısından başarılı olmuştur.

Nihayet, tüm bu çabalar sonuçlarını Konferans'ın Gündem 21'inde göstermiş ve "Kadınlar" bu resmi belgede Gündem 21'in uygulanması için dokuz ana gruptan birisi olarak yer almıştır. Kadınların sürdürülebilir kalkınma içindeki rolünün tanınması ve kadınların rolünün iyileştirilmesi için belirli eylemlerin belirlenmesi çok yararlı olmuştur.

Tüm bu uluslararası süreçlerin dışında, kadınlar arasında sürdürülebilir kalkınma için tematik bir organizasyon ve bölgesel bir anlaşma olmuştur. 1990'ların başından bu yana, "Kadın ve Su İttifakı", "Kadın İçin Çeşitlilik" ve "ENERGIA" gibi gruplar kurulmuştur. Orta Amerika'da Uluslararası Dünya Doğayı Koruma Birliği (IUCN)'in gösterdiği çabalar çevre açısından cinsiyet analizlerinin yapılmasını ve kadın organizasyonlarının güçlenmesini sağlamıştır.

\section{Sonuç Yerine}

Çevresel değişiklikler ve iklim değişikliği tüm insanlığı olumsuz etkilemektedir. Ancak bu değişiklikler kadınların yaşamlarını erkeklere oranla mevcut toplumsal cinsiyet dinamikleri ve eşitsizlikler nedeniyle farklı şekillerde etkilemektedir. Bunun sonucunda toplum içindeki değişen rolleri kadınların ve erkeklerin strateji ve seçimlerle başa çıkma yöntemlerini etkileyebilmekte ve onların sürdürülebilir kalkınmada önemli bir aktör olmalarını sağlamaktadır. Dankelman (2002: 28) bu çalışmasında iklim değişikliği ve toplumsal cinsiyet bağlamında Kadın örgütleri çevre ve kalkınma alanında 15 yıl önce aktif olmaya başlayan çalışmalara yer vermiş ancak hala olgunlaşamamış olduklarını da belirtmiştir. 
Kadın örgütlerinin iyi iletişim ağına sahip olması ve aynı zamanda yerel, ulusal ve küresel alanlarda ses getirmesi elzemdir. Bunların yanı sıra adaptasyon, uyum, azaltım, teknoloji ve finansman gibi konularda kadınların göz önünde bulundurulduğu kolektif çabaların iklim değişikliğinin olumsuz etkileriyle başa çıkma konusunda başarı sağlanması açısından ne denli önemli olduğu açıktır. Kadınların ihtiyaçlarının göz ardı edilmediği ve çevresel kalkınmanın desteklendiği alanlar ile küresel politika geliştirme ve karar verme alanlarında daha baskın olmaları iklim değişikliğinin olumsuz etkilerinden görece daha az etkilenmeleri yolunda atılacak önemli adımlardır.

\section{Kaynakça}

Dankelman, Irene (2002), "Climate Change: Learning from Gender Analysis and Women's Experiences of Organising for Sustainable Development", Gender \& Development, 10 (2): 21-29.

Lambrou, Yianna ve Piana Grazia (2006), Energy and Gender Issues in Rural Sustainable Development (Rome: $\mathrm{ftp}: / / f t p . f a o . o r g / d o c r e p / f a o / 010 / a i 021$ e/ai021e00.pdf.

Shiva, Vandana (2010), Yeryüzü Demokrasisi: Adalet, Barış ve Sürdürülebilirlik (BGST: İstanbul).

UN (2015), The Millenium Development Goals Report. http://www.undp.org/content/dam/undp/library/MDG/english/UNDP_MDG_Repo rt_2015.pdf

UNEP (2016a), Gender Equality and Environment: A Guide to UNEP'S Work. http://apps.unep.org/redirect.php?file=/publications/pmtdocuments/Gender_equ ality_and_the_environment_A_Guide_to_UNEPs_work2016Gender_equality_and_the_environment.pdf.

UNEP (2016b), Global Gender and Environment Outlook 2016: The Critical Issues. http://uneplive.unep.org/media/docs/assessments/GGEO_summary_report.pdf]

UN-Womenwatch (2016), Factsheet: Women, Gender Equality and Health in the Context of Climate Change. http://www.un.org/womenwatch/feature/climate_change/downloads/Women_an d_Climate_Change_Factsheet.pdf.

WHO (2007), Climate Change and Health: Preparing for unprecedented challenges, Keynote statement of Dr. Margaret Chan. Director General of the World Health Organization at the U.S. National Institutes of Health, Maryland, USA. 


\section{EK KAYNAKLAR}

Hart, Kimberly (2011), Modernliği Dokumak: Bir Batı Anadolu Köyünde Hayat, Aşk, Emek (İstanbul: Koç Üniversitesi Yayınları).

McCright, Aaron M. (2010), "The Effects of Gender on Climate Change Knowledge and Concern in the American Public", Population and Environment, 32 (1): 66-87. http://www.jstor.org/stable/40984168?seq=1\#page_scan_tab_contents.

Shiva, Vandana (2014), Iyilerin Yanında: Çiftçi Haklarına Adanmış Bir Yaşam (İstanbul: Sinek Sekiz).

Talu, Nuran (2015), Türkiye'de Iklim Değişikliği Siyaseti (Ankara: Phoenix).

UNEP (2015), Our Planet: Women, Health and Environment, 15 (2). https://digital.library.unt.edu/ark:/67531/metadc28517/m2/1/high_res_d/OurPlan et2004_WomenHealthEnv.pdf

UNEP (2016), Gender Equality and The Environment: Policy and Strategy. http://drustage.unep.org/gender/resources/gender-policy-related-documents.

UNFCCC (2014), United Nations Framework Convention on Climate Change Decisions and Conclusions: Existing Mandates and Entry Points for Gender Equality. Gender and Climate Change. http://www.wedo.org/wp-content/uploads/GEPublication-ENG-Interactive.pdf.

UN-Water (2006), Gender, Water and Sanitation: A Policy Brief. http://www.unwater.org/downloads/unwpolbrief230606.pdf. 